\title{
A Methodology for the Experimental Validation of an Aircraft ECS Digital Twin Targeting System Level Diagnostics
}

\author{
Shafayat Hasan Chowdhury ${ }^{1}$, Fakhre $\mathrm{Ali}^{2}$, and Ian K. Jennions ${ }^{3}$ \\ 1, 2, 3 IVHM Centre, Cranfield University, Bedfordshire, MK43 OAL, United Kingdom \\ shafayat.chowdhury@cranfield.ac.uk \\ f.ali@cranfield.ac.uk \\ i.jennions@cranfield.ac.uk
}

\begin{abstract}
${ }^{1}$ The Environmental Control System (ECS) of an aircraft is responsible for regulating and conditioning the airflow into the cockpit, cabin and avionics bay. The ECS is composed of several complex sub-systems and components that are reported as key unscheduled maintenance drivers for legacy aircraft by aircraft operators. Furthermore, the incorporated temperature and flow control valves in these sub-systems have the capability to mask potential faults at the component level, making the diagnostic process very challenging. To overcome this challenge, the aviation industry is currently proactively exploring the predictive maintenance approach that allows real-time monitoring of the key systems, subsystems and components. In the context of the ECS, this necessitates the requirement to equip the system with appropriate condition monitoring capabilities. To do this, the performance characteristics of the ECS at sub-system and component level needs to be well understood under a wide range of aircraft operating scenarios. Existing literature provides both the component-level and systemlevel analyses of the ECS. However, it lacks an experimentally verified and validated ECS sub-system and component level simulation tool (ECS Digital Twin), capable of simulating the thermodynamic performance and component health state parameters under wide-ranging aircraft operational scenarios. The ECS Digital Twin (DT) developed by the Cranfield University IVHM Centre offers the capability to simulate healthy and faulty cases of the Passenger Air Conditioner (PACK). This paper proposes a methodology for full-scale experimental Verification \& Validation $(\mathrm{V} \& \mathrm{~V})$ of the developed ECS DT, to enable

\footnotetext{
$1_{\text {Shafayat Chowdhury et al. This is an open-access article distributed under }}$ the terms of the Creative Commons Attribution 3.0 International License, which permits unrestricted use, distribution, and reproduction in any medium, provided the original author and source are credited
}

component-level simulation, and enabling accurate diagnostics, of the civil aircraft ECS. The paper reports on progress to date in this project.

\section{INTRODUCTION}

The ECS of an aircraft regulates the supply of conditioned airflow throughout the cabin. The overall ECS is composed of several complex subsystems that are prone to degradation and can, therefore, lead to failure, compromising the system functionality and increased unscheduled maintenance activity. This leads to the ECS being a major driver for maintenance and necessitates the requirement for identifying and developing a condition-based monitoring approach, enabling systematic diagnostics to minimise unscheduled maintenance as well as maximising system safety.

In this study, an experimentation plan has been designed and proposed to facilitate a comprehensive step-by-step $\mathrm{V} \& \mathrm{~V}$. The successful implementation of the proposed methodology ensures the acquisition of a robust experimental data set that is vital for enabling the development of a sophisticated diagnostic algorithm for fault detection and isolation of the ECS under a wide range of aircraft operational scenarios. Furthermore, the instrumentation set identified through the proposed methodology in terms of temperature, pressure, mass flow and humidity sensors allow a systematic understanding of ECS performance characteristics and quantification of ECS failure modes. This is necessary for the development of an effective model-based diagnostic rule for the ECS.

\section{AirCRAfT MaintenanCE}

In the aviation industry, manufacturers are required to ensure the continuing airworthiness of the aircraft, which includes maintenance, repair and overhaul, to maximise aircraft operational availability. The preventive maintenance 
process starts with regular checks, or in some cases with a fault report. As shown in Figure 1, after a certain number of flight hours, or once a fault is reported, the aircraft is grounded, and data is collected for diagnostic purposes. Based on the diagnostic results, maintenance plans are prepared. Once the desired maintenance activity is successfully implemented and verified, the aircraft is authorised to fly again. This type of approach generally leads to unnecessary downtime, impacting the aircraft availability, and therefore, leads to an increase in operating cost.
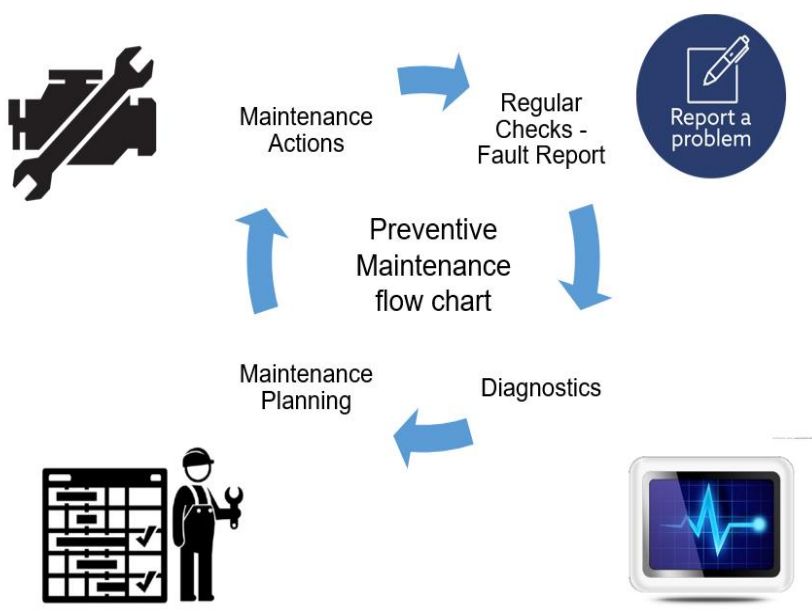

Figure 1. Preventive maintenance flow chart

To eliminate unnecessary maintenance cost, the aerospace industry is proactively exploring the shift towards predictive maintenance. This approach aims to replace the 'Regular Checks' step in Figure 1 with continuous condition monitoring to enable diagnosis based on the acquired realtime data. The data is further used to project estimation of the Remaining Useful Life (RUL) of the key sub-system; this information allows the determination of time between failures and therefore enables systematic and efficient planning of the required maintenance actions, necessary for achieving maximum aircraft operational availability and safety. Through this study, optimal sensor sets, and diagnostic rules will be explored.

\subsection{Fault Detection and Isolation Approaches}

In the past, different fault detection and isolation (FDI) capabilities have been extensively researched. These can be broadly categorised in three approaches: (i) Data-Driven (Lightfoot \& Greenough, 2016), (ii) Model-based (Cubillo, Perinpanayagam, \& Esperon-Miguez, 2016) and (iii) Hybrid (Jung, Ng, Frisk, \& Krysander, 2018). Data-driven methods require a vast amount of data for extracting features and training FDI algorithms, as highlighted in research (Daigle \& Goebel, 2011; Yang, Jin, Du, \& Zhu, 2011). Researchers like Saxena and Saad (Saxena \& Saad, 2007) suggested the model-based approach to be ideal for complex systems such as the ECS with multiple fault modes. The model-based approach uses system dynamics and mathematical modelling to generate a residual outcome from the actual system and the simulation model output, providing a better understanding of the failure modes (Butler, 2012). In the case of the ECS, fouling detection in the heat exchanger using a model-based approach is reported using: extended Kalman filter (Jonsson, Lalot, Palsson, \& Desmet, 2007), double model filter (Pang, Qu, \& Dong, 2008). Thus, based on the literature review, model-based diagnostic approach to detect fault occurrences in the ECS is targeted in this project.

\subsection{ECS Digital Twin}

Although the component-level condition monitoring has been widely researched, the open literature lacks exhaustive research work on a system-level approach. FLECS (C. Müller, D. Scholz, 2007; Scholz, Giese, \& Erdmann, 2007) is a system-level simulation platform for an ECS and contains healthy models of different ECS components. Test data (temperature readings) at the PACK outlet and the cabin were used to verify the model. Flowmaster (Y. Tu \& Lin, 2011; Yi Tu \& Lin, 2010) is another simulation package, verified against temperature readings that are collected through experimentation. Boeing's EASY5 (Burroughs \& Hammond, 1983) was used to model the ECS for both Civil and Military aircraft. However, systematic validation of the employed ECS model against experimentally acquired pressure, temperature and mass flow data has not been reported. With inspiration from EASY5, the Modelica programming language has been used to model an ECS in Dymola (Steinkellner, 2011; Steinkellner, Andersson, \& Gavel, 2009).

Amongst all these approaches, it has been identified that the experimental validation was not comprehensive and was dependent mostly on temperature readings collected at specific locations. To address this, the IVHM Centre has recently developed a digital twin for condition monitoring and diagnosis of the ECS (Escobar, 2015), which will be validated based on the methodology proposed in this study. The salient features of the developed DT are:

- It provides a generic ECS component library, allowing the capability to simulate a wide-range of ECS design architectures.

- It incorporates the ability to model degradation at the component level.

- It allows the assessment of component-level design characteristics, system thermodynamics parameters, and humidity. 


\section{ENVIronMENTAL CONTROL SYSTEM}

The ECS of an aircraft consists of three different complex subsystems to provide conditioned air with the correct temperature, pressure and humidity: (i) Bleed Air System (BAS), (ii) PACK and (iii) Air Distribution System (ADS). While the aircraft is in the air, bleed air from the engine compressor is used to power the ECS. On the ground, the ECS is driven by the Auxiliary Power Unit (APU). In both cases, the PACK regulates the thermodynamic parameters of the air. The airflow is then filtered and distributed to the cockpit, cabin and the avionics bay.

\subsection{Passenger Air Conditioner}

The PACK is the primary system for conditioning the flow within the ECS, which makes it the primary focus of this study. Figure 2 illustrates the schematic of a single PACK in the B737-400. It consists of Valves, Heat Exchangers, an Air-Cycle Machine (ACM) and a High-Pressure Water Separator (HPWS).

At the beginning of the PACK is the PACK valve (PV) that regulates airflow through the system. The PV controls airflow towards the Temperature Control Valves (TCV) and the core. The airflow splits into two streams: one enters the core through the Primary Heat Exchanger (PHX), and the other enters into the TCVs. The PHX allows for heat exchange between the hot compressed air from the engine compressor and the surrounding cold RAM air. The air then goes into the compressor of the ACM where the air is compressed, creating the pressure difference to drive the air through the system. The air further goes through the Secondary Heat Exchanger (SHX) which enables further heat exchange with the RAM air. The air then flows through the Reheater (RHX) and the Condenser (CHX). This drops the temperature further and initiates condensation of water droplets which are then drained out from the two Water Separators (WS). This part of the core is known as the HPWS. The RHX and CHX work as heat exchangers: the cold air from the WS outlet travels through the RHX, then further into the turbine. Energy is extracted from the air within the turbine to drive the compressor. As the temperature in the turbine outlet drops significantly, the two TCVs open and allow the hot bleed air to mix at the turbineTCV merge. The cold air then flows through the CHX and out of the PACK.

The turbine inlet, compressor discharge and PACK discharge overheat switches controls the opening and closing of the valves. The PACK temperature sensor located at the outlet of the WS and the RAM air temperature sensor data is used by the aircraft zone temperature controller to regulate the PACK outlet temperature by varying the degree of valve opening.

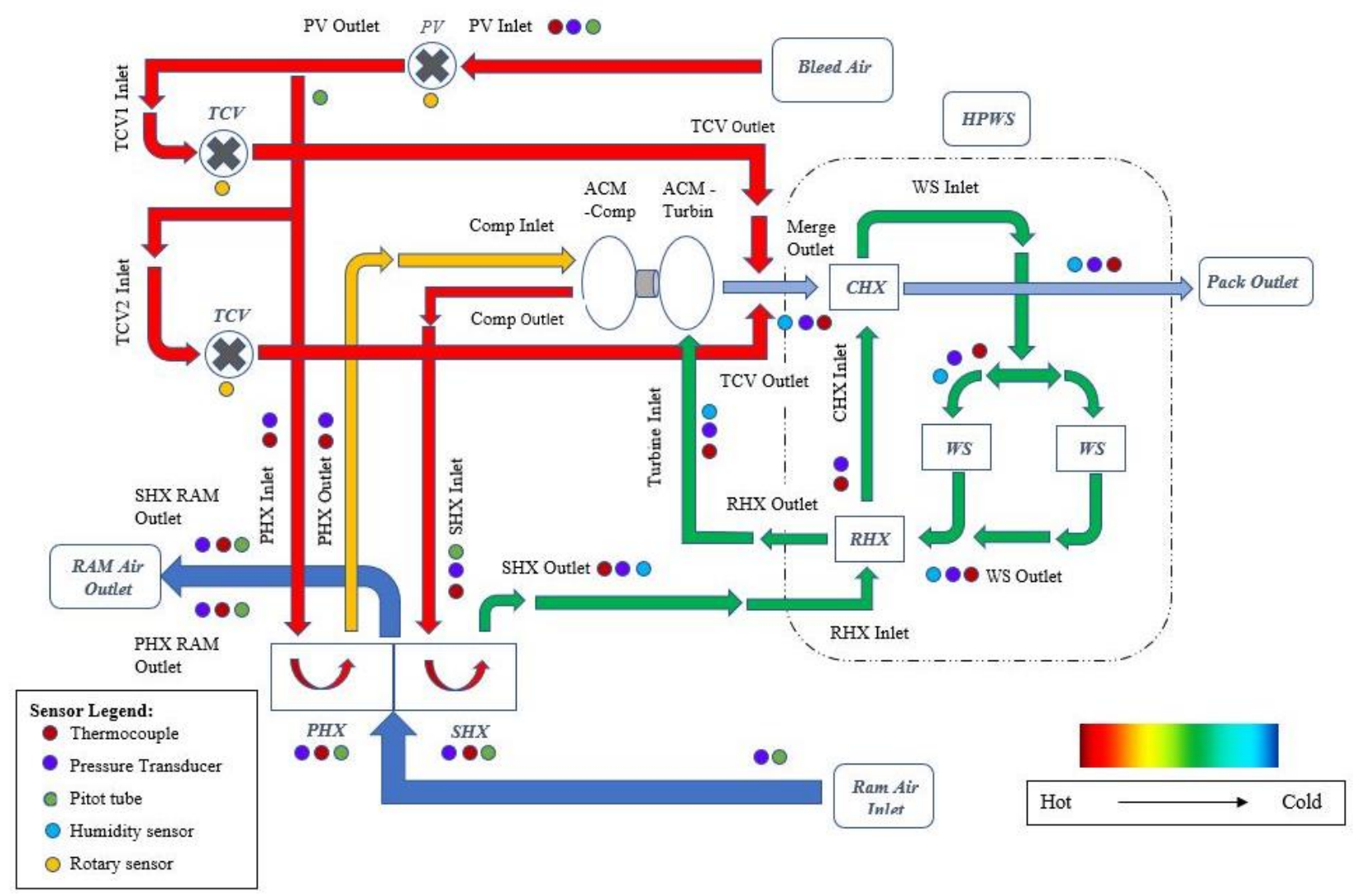

Figure 2. B737-400 PACK schematic with sensor installation 


\section{Verification \& VAlidation Process}

There is a compelling need to acquire comprehensive sets of data from the ECS systems for $\mathrm{V} \& \mathrm{~V}$ of the DT developed at the IVHM Centre. Cranfield University's B737-400 will be used in this experiment to heavily instrument the ECS with sensors. This will allow a complete understanding of different fault modes within the ECS, which is essential for model-based FDI. Furthermore, the interdependencies between the components will also be analysed.

\subsection{Methodology}

This research work consists of 4 phases: experimentation, simulation, V\&V, and diagnostics, as shown in Figure 3. To develop a ground test facility (GTF), the left-hand side PACK was removed from Cranfield's B737-400 aircraft. Sensors were selected, tested and installed. The sensor installation locations are shown in Figure 2. With all the sensor installed the PACK was refitted back in the aircraft. The sensors were all connected to a data acquisition unit (DAQ) inside the ECS bay.

A simulation model for the designated ECS will be formed using the component library developed at the IVHM Centre. The sensor readings at the PV inlet (i.e. PACK inlet temperature, pressure, humidity and mass flow rate) will be treated as healthy and used as input parameters to the DT.
The experimental data set, and the simulation result will then be compared for $\mathrm{V} \& \mathrm{~V}$ of the digital twin. The optimal sensor set for fault detection and diagnostic rules (Figuero, 2017) will also be verified. If necessary, alterations will be made to the component library and ECS model. Diagnostic algorithms will then be written and validated using the experimental data.

\subsubsection{Simulation}

The B737-400 model developed was initially calibrated by using the test cases provided by industrial partner The Boeing Company. Data collected from the model includes temperature, pressure, mass flow, valve angle and efficiency of the components (i.e. ACM, RHX, CHX, PHX, SHX). Once the healthy case results were achieved, fault simulation results will be analysed, starting with PHX degradation. Component degradation and failure modes are simulated as deviations in the health indicating parameters (e.g. decrease in heat exchanger effectiveness). Once the experimental data is collected, the model library will be calibrated to achieve an accurate model. Finally, the specific humidity and water content analysis capability will be incorporated into the model, which is a novel approach in investigating aircraft ECS.

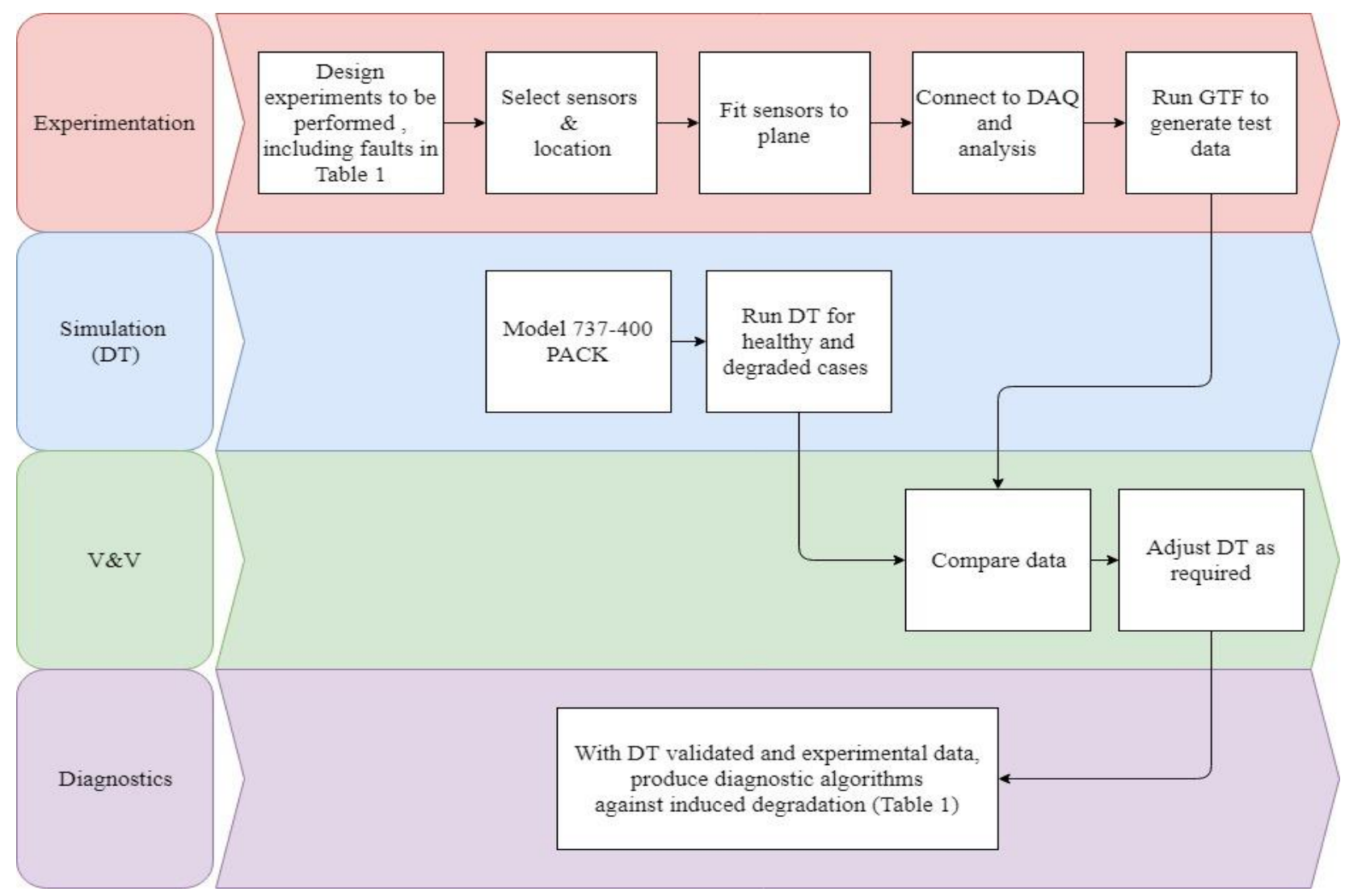

Figure 3. Research Methodology 


\subsubsection{Experimentation}

As mentioned at the beginning of this section, all experimental work will be performed on Cranfield's B737400 aircraft. All the experiments will be repeated under three different cabin zone temperature control setting (i.e. the individual temperature selectors at the cockpit, forward cabin and aft cabin will be set for the given cabin demand):

(i) $5^{\circ} \mathrm{C}$, (ii) $18^{\circ} \mathrm{C}$ and (iii) $30^{\circ} \mathrm{C}$.

In addition to healthy case experimentations, a wide-range of cases, representing degradation in components, will also be explored to validate the DT. The experiments will be carried out targeting various functional faults, tabulated in Table 1. It is to be noted that the faults listed are the preliminary list and are likely to evolve throughout experimentation. As mentioned in section 3.1, the PACK is heavily dependent on the sensors readings to regulate the valve opening. These sensors are prone to degradation; however, the sensor faults will not be investigated in this project. Only the functional faults in the components will be considered.

Table 1. Preliminary list of faults that will be experimentally tested

\begin{tabular}{|c|c|c|c|}
\hline Fault modes & \multicolumn{3}{|c|}{ Conditions } \\
\hline $\begin{array}{c}\text { Heat exchanger } \\
\text { fouling (PHX and } \\
\text { SHX) }\end{array}$ & $\begin{array}{c}1 / 4 \\
\text { blocked }\end{array}$ & $\begin{array}{c}1 / 2 \\
\text { blocked }\end{array}$ & $\begin{array}{c}3 / 4 \\
\text { blocked }\end{array}$ \\
\hline $\begin{array}{c}\text { Valves } \\
\text { malfunctioning (PV } \\
\text { and TCV) }\end{array}$ & \multicolumn{3}{|c|}{$\begin{array}{c}\text { Between } 0 \% \text { open }-100 \% \text { open in } \\
\text { intervals of } 10 \%\end{array}$} \\
\hline $\begin{array}{l}\text { Ram air door } \\
\text { sticking }\end{array}$ & \multicolumn{3}{|c|}{$\begin{array}{c}\text { Between } 0 \% \text { open }-100 \% \text { open in } \\
\text { intervals of } 10 \%\end{array}$} \\
\hline
\end{tabular}

The average duration of each test has been estimated to be 10 minutes. This includes the time necessary to reach steady-state conditions, capture data, and the time necessary to start and shut down all the necessary systems of the aircraft. Within this time frame, thermodynamic parameters (pressure, temperature and mass flow), humidity and valve angular position will be recorded.

\section{EXPERIMENTAL SETUP}

The left-hand side PACK from the B737-400 was removed from the aircraft. The ducts were dismantled and taken out, including the PV and TCVs. The ACM and HPWS came out as single units. The disassembled PACK is shown in Figure 4.

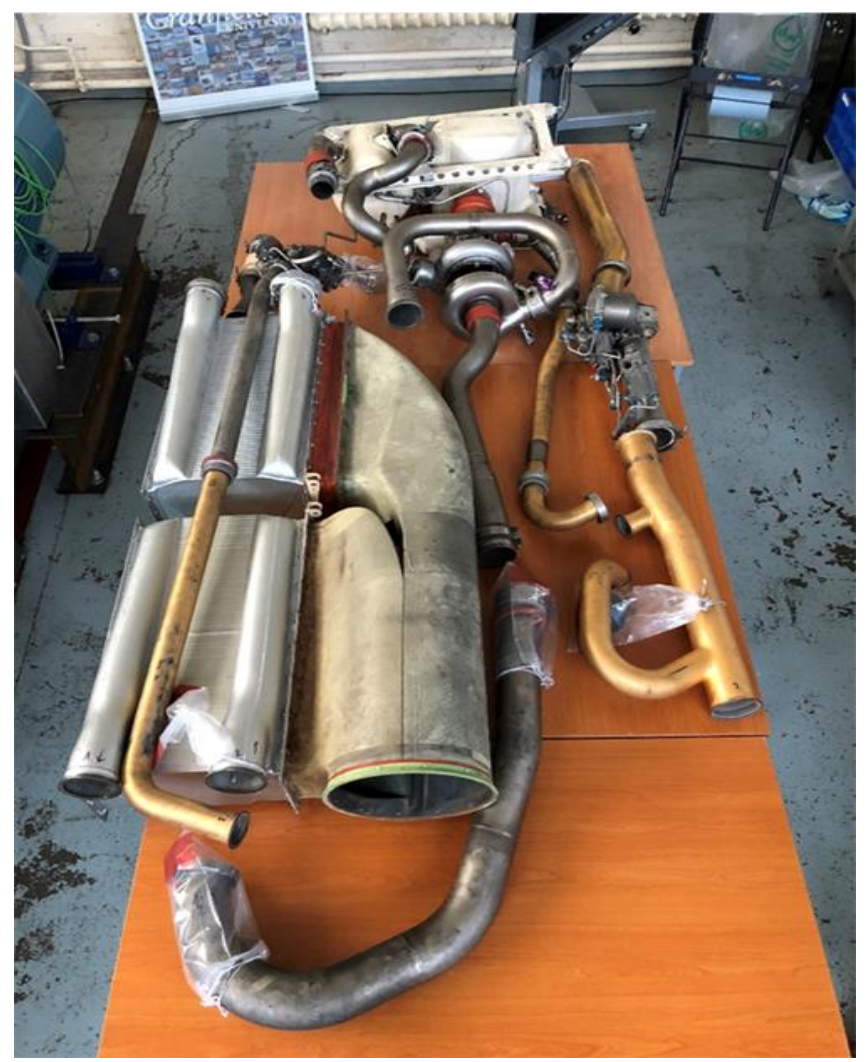

Figure 4. B737-400 Left-hand side PACK

Sensor bosses were then manufactured and welded onto the selected locations on the PACK. One of the restrictions with sensor selection was the availability of space for sensor installation. This means the angle at which the sensors are installed significantly impacts the final assembly process of the PACK. To accurately install the sensors, the locations were identified by referring to the right-hand side PACK of the aircraft. Figure 5 shows the SHX inlet duct with a pressure transducer, thermocouple and total pressure head installed.

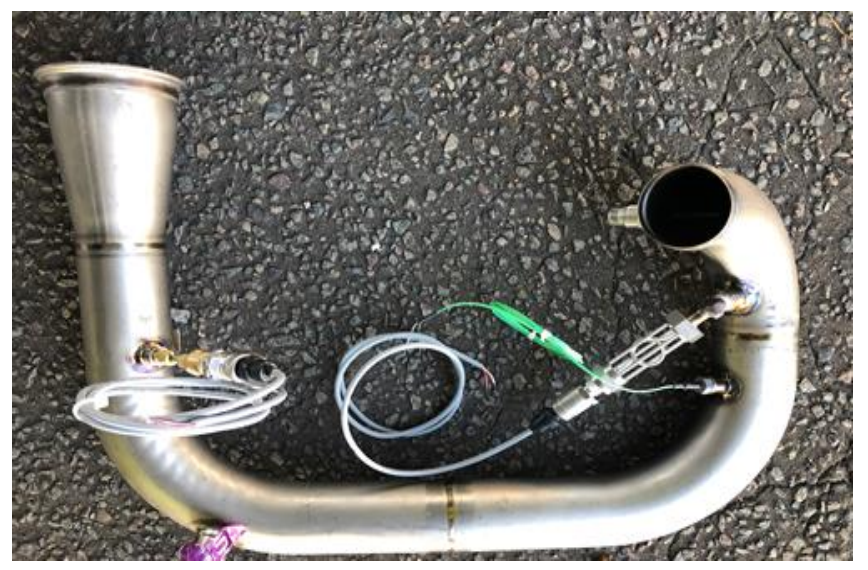

Figure 5. SHX inlet duct with sensors installed 


\subsection{Sensor Selection}

Based on the previous studies on the ECS (Figuero, 2017), operating temperature and pressure range throughout the system is estimated to be $-33.15^{\circ} \mathrm{C}$ to $+186.85^{\circ} \mathrm{C}$ and 100 $\mathrm{KPa}$ to $350 \mathrm{KPa}$. However, no previous data on the humidity was available. Thus, this experiment will be contributing directly to understanding the change in humidity within the HPWS. A total of 56 sensors have been installed, which will provide a clear understanding of the system performance characteristics.

Due to the high temperature in specific locations on the PACK, the sensors were carefully selected with a higher operating temperature range. For pressure sensors with a maximum functional limit at $125{ }^{\circ} \mathrm{C}$, temperature isolation coils were used to match the sensor installation temperature requirements. The k-type thermocouple was selected with a maximum temperature rating of $+400{ }^{\circ} \mathrm{C}$ to allow temperature measurements at the upper bound of the PACK operation. However, due to the design constraints associated with the humidity sensors for operating in higher temperature regions, the selection of installation locations was carefully identified to comply with the sensor operating temperature range. Table 2 shows the breakdown of the number of sensors installed in the PACK.

Table 2. List of sensors installed in the PACK

\begin{tabular}{|c|c|c|}
\hline Sensors & Quantity & $\begin{array}{c}\text { Operating } \\
\text { Temperature Range }\end{array}$ \\
\hline Pressure Transducer & 16 & -40 to $+125^{\circ} \mathrm{C}$ \\
\hline $\begin{array}{c}\text { Intrusive } \\
\text { Thermocouple }\end{array}$ & 15 & -100 to $+400^{\circ} \mathrm{C}$ \\
\hline $\begin{array}{c}\text { Non-intrusive } \\
\text { thermocouple }\end{array}$ & 8 & -195.556 to $+287.778^{\circ} \mathrm{C}$ \\
\hline Humidity Sensor & 6 & -40 to $+85^{\circ} \mathrm{C}$ \\
\hline Rotary Sensor & 3 & $+150^{\circ} \mathrm{C}$ \\
\hline Pitot-tube & 8 & - \\
\hline
\end{tabular}

\subsection{Sensor Locations on the PACK}

The sensors, selected in the previous section, were fitted at the inlet and the outlet of each component within the PACK. Due to the high temperature at the PACK inlet, humidity sensor could not be fitted in this region. They were also excluded from the RHX outlet (hot side) due to the spacing constraint. Therefore, the humidity sensors were only fitted at six locations from the HPWS inlet (through the RHX) to the PACK outlet.

Pressure and temperature sensors were installed throughout the PACK at the input and output of each component. In order to measure the mass flow through the system, pitot- tubes were fitted at eight different locations. These include the PACK inlet, the PACK valve outlet (at the first split for the mass flow rate through TCV 1) and the Compressor outlet (for the mass flow rate through the core). The mass flow rate through the TCV 2 will be calculated by the mass flow readings from the existing pitot-tubes. The flow rate at the RAM air inlet door and the inlet and outlet through both PHX and SHX will also be recorded from the pitot-tube fitted on these locations. The rotary sensors were installed on three valves: the PV and the two TCVs.

\subsection{Sensor Tests}

In order to avoid a non-functioning sensor being inadvertently fitted to the aircraft, all sensors were tested prior to installation. The pressure transducers were connected to a power supply of 5 VDC and grounded to test the electric connection and functionality of the sensors. The sensors were verified by measuring atmospheric pressure. The rotary sensors used to measure the valve angle were explicitly manufactured to measure a maximum of $90^{\circ}$ clockwise rotation. With regards to the mass flow measurements, specifically tailored pitot-static tubes, were manufactured and tested using in-house capabilities at Cranfield's Gas Turbine Engineering Laboratory.

As shown in Figure 6, the humidity sensor was connected to a power supply. About $32 \%$ relative humidity was obtained at room temperature. The sensor was then held on top of steam (boiling water in the mug shown) to measure relative humidity. A reading of $98 \%$ relative humidity was obtained, thus verifying that the sensor is working.

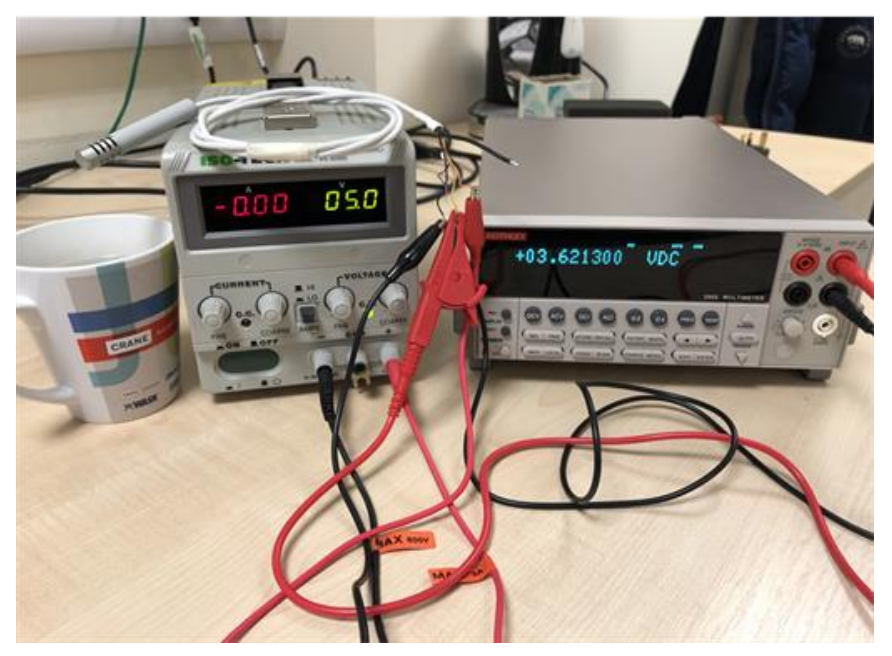

Figure 6. An experimental test for relative humidity measurement of steam

The humidity sensor required a compression fitting, which uses a ferrule to seal the space between the sensor and the boss welded on the designated installation location. Figure 7 demonstrates the pressure test conducted on the humidity sensor to verify it's fitting. 


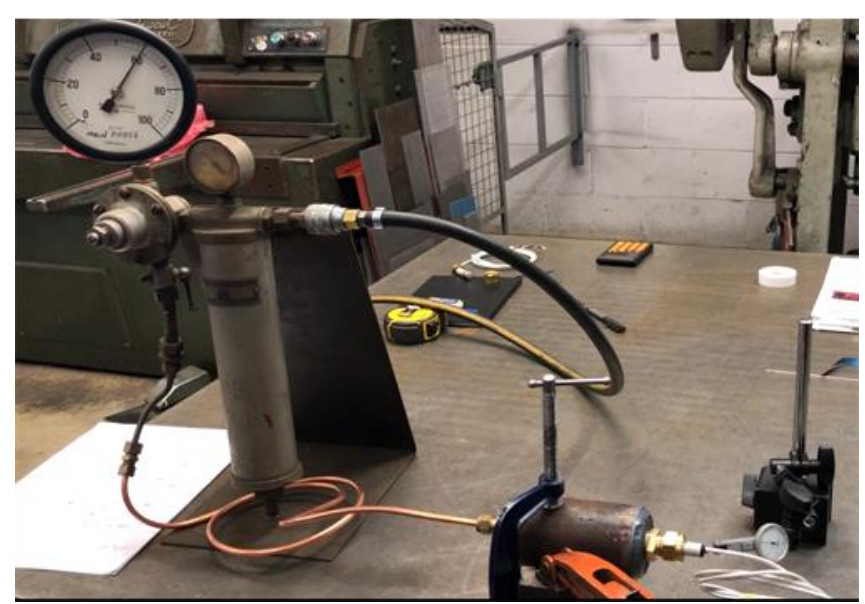

Figure 7. Experimental setup for compression fitting test on the humidity sensor

\subsection{Ground Test Facility}

The PACK was re-installed into the aircraft with all the sensors fitted in position. The ECS was powered by the APU for 10 minutes to conduct functionality test. The PACK was further tested for leakages, especially where sensor bosses were welded.

The cables from the sensors were connected into the DAQ and power supply to the sensors which were securely installed inside the ECS bay on a DIN rail. An ethernet cable from the DAQ was taken out and routed to the cabin through the landing gear inspection window, situated in the cabin floor. This way of connecting the sensors allows the ECS bay door to be closed and to have a lab environment inside the cabin to facilitate this research work and for future projects ensuring repeatability of the experiments, making this a unique GTF.

The DAQ includes voltage input modules (for pressure transducers, rotary sensors and humidity sensors) and temperature input modules (for thermocouples). As the experimental data will be collected at steady-state and at $1 \mathrm{~Hz}$, the voltage input modules and temperature input modules were selected with a minimum rating of $10 \mathrm{kHz}$ and $50 \mathrm{~Hz} / \mathrm{ch}$ respectively. The NI LabVIEW software package will be used for data acquisition and visual representation of the data being collected.

\section{Simulation RESUltS}

In this section, the healthy and degraded case simulation results are presented and discussed, including a possible approach towards the development of the model-based diagnostic rule.

\subsection{Healthy Case Simulation}

An initial test run of the DT developed at the IVHM Centre was conducted at the ground condition. Table 3 shows the input parameters used to obtain simulation results. In the first simulation, the components (i.e. heat exchangers, ACM, CHX and RHX) were modelled to be in a healthy state.

Table 3. Input parameters for running simulation at ground level

\begin{tabular}{|c|c|}
\hline Altitude & Ground \\
\hline Mach & 0 \\
\hline Bleed air temperature & $188.1^{\circ} \mathrm{C}$ \\
\hline Bleed air pressure & $305.024 \mathrm{kPa}$ \\
\hline Cabin target pressure & $101.325 \mathrm{kPa}$ \\
\hline Cabin target temperature & $15^{\circ} \mathrm{C}$ \\
\hline Cabin target mass flow & $0.52 \mathrm{~kg} / \mathrm{s}$ \\
\hline RAM air temperature & $23.889^{\circ} \mathrm{C}$ \\
\hline RAM air mass flow & $0.706 \mathrm{~kg} / \mathrm{s}$ \\
\hline
\end{tabular}

The outputs - temperature and pressure - across the PACK are graphically represented in Figure 8-9 respectively. The dots represent the obtained simulated value at each output of the individual component of the system, and the dashed lines are added to obtain a visual representation of the temperature-pressure profile throughout the PACK subsystems. The model was not designed for any leakages in the ducts or the sub-systems of the PACK, and so this led to a constant mass flow rate through the system.

\subsection{Fault Condition Simulation}

The failure modes identified were also simulated. In this paper, the PHX degradation and its effect on the temperature and pressure profile are shown. For the input parameters as shown in Table 3, ten simulations were conducted with the PHX degradation severity level from 1 to 0.1 with a decrement of 0.1 (where 1 being healthy and 0 being completely failed). The temperature and pressure profile obtained from the simulation is shown in Figure 1011. In Figure 10, a gradual decrease in heat transfer across the PHX is noticed as the PHX was gradually degraded. Since the effectiveness of the PHX has dropped, the heat transfer rate was affected. The air then goes through the compressor, where a rise in temperature was noticed due to the compression of hot air. However, the SHX was noticed to work as an efficient heat sink to drastically drop the air temperature close to the target temperature. This temperature drop across the SHX was achieved by the temperature control loop detecting a higher temperature at the compressor discharge duct and reducing the mass flow through the PV. Hence a pressure difference for different 
PHX degradation level is noticed at the PV outlet, as shown in Figure 11.

By analysing all the graphs obtained for the healthy case and PHX degraded cases, it is evident that the control logic to drive the PV and TCV to regulate the temperature and pressure across the system is quite robust. Furthermore, a reduction in heat transfer across the PHX and pressure drop across the PV can indicate PHX degradation.

\subsection{Diagnostic Rule Development}

The final aim of this project is to use the DT and experimental data to develop a model-based diagnostic rule for the PACK. The combination of having a fully-functional model and experimental data to verify the physics, upon

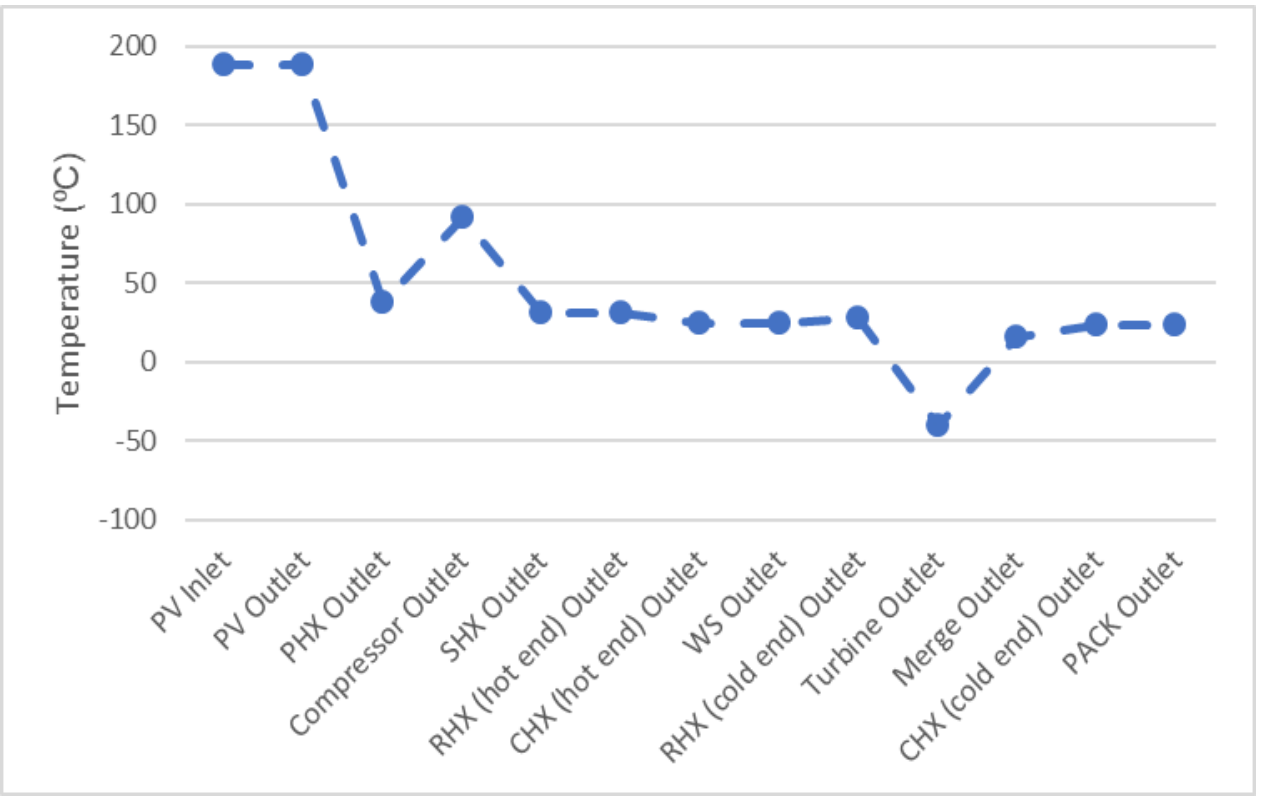

Figure 8. Temperature profile across the PACK obtained from simulation

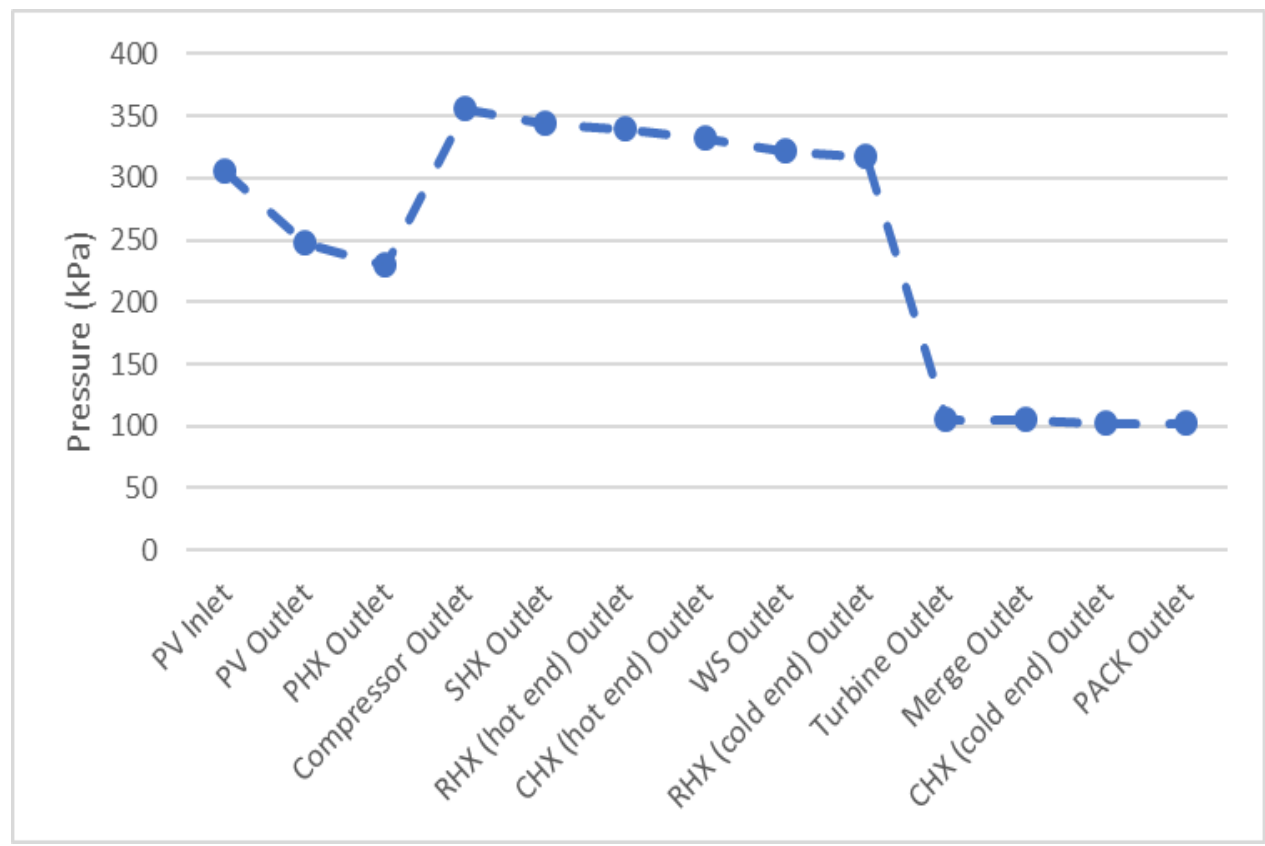

Figure 9. Pressure profile across the PACK obtained from simulation 


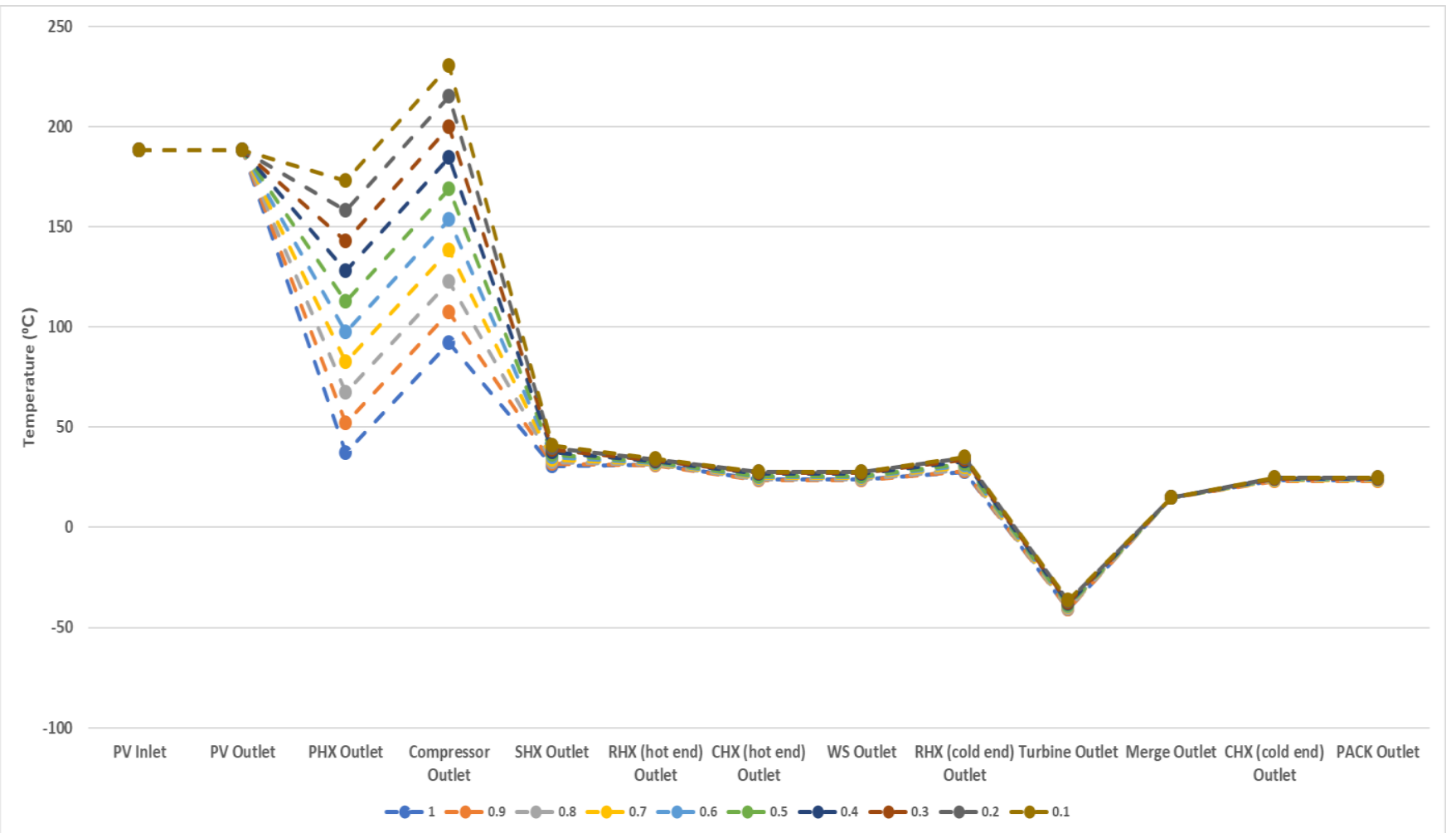

Figure 10. Temperature profile across the PACK with the PHX degradation

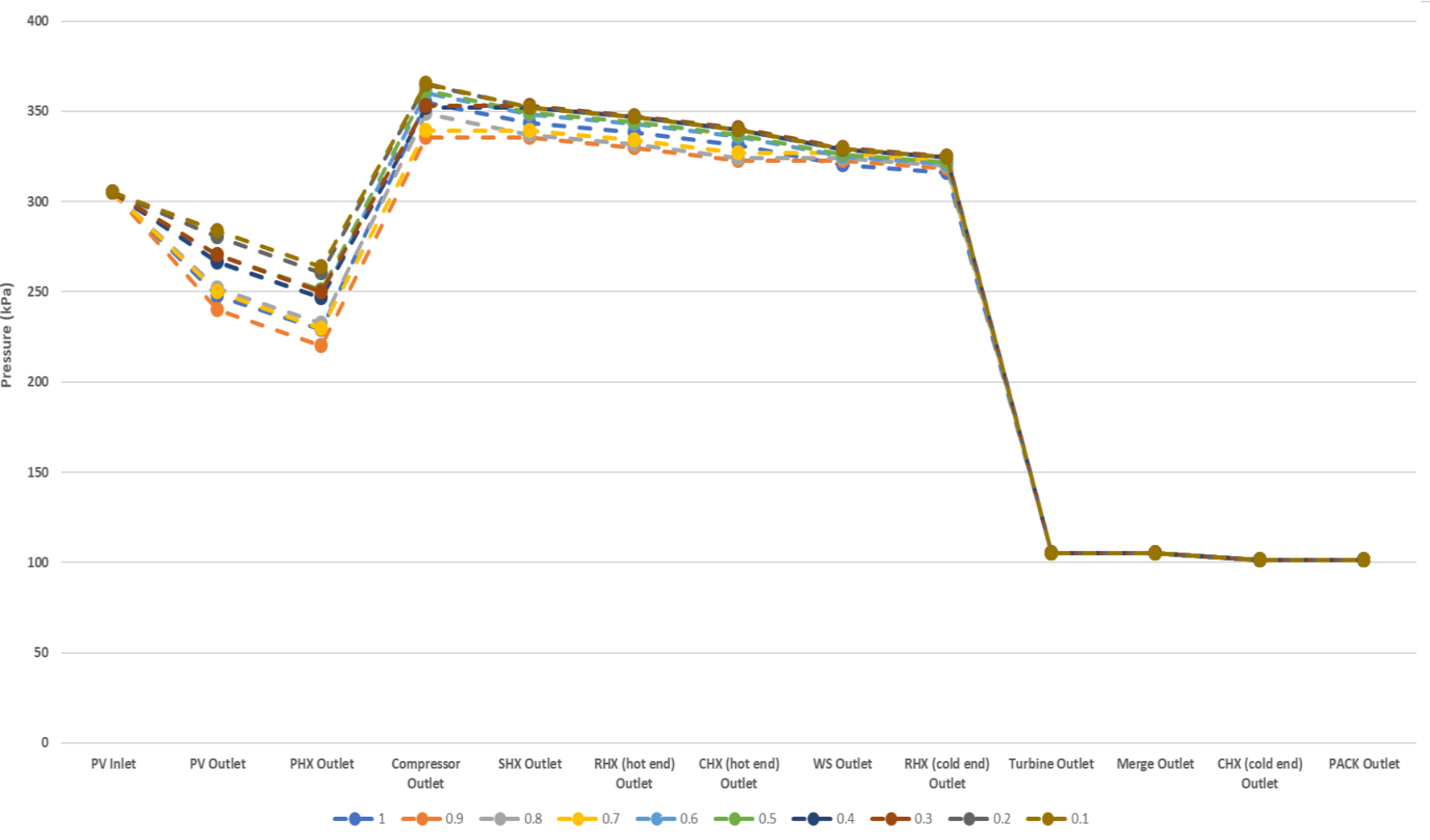

Figure 11. Pressure profile across the PACK with the PHX degradation 
which the model was developed, will be instrumental in obtaining a clear understanding of the performance characteristics of the system under both healthy and degraded scenarios. This knowledge is essential and supports the development of a model-based diagnostic rule, as opposed to the data-driven method, which requires an extensive amount of data to train the algorithm. The diagnostic rule will include an optimised sensor set selection for fault detection and isolation. This will also be later verified using rich experimental data collected from the GTF developed. Lastly, the humidity profile for the PACK will be developed. The data collected will be analysed for specific humidity and water content across the PACK. The DT will be appropriately modelled to calculate the humidity and water content for any given case and plot specific humidity and water content profile along with the temperature and pressure profile.

\section{CONCLUSION}

This paper proposes a methodology targeting the full-scale cost-effective experimental testing and $\mathrm{V} \& \mathrm{~V}$ of a civil aircraft ECS DT at the component level. Although the experimental work will be on the ground, as the DT is physics-based, the successful implementation of the devised methodology is seen as an essential first step in the development of a robust ECS DT, capable of performing a comprehensive evaluation of the ECS performance. This will also enable the development of fault detection and isolation capability for the ECS PACK. The experimental plan for acquiring the system thermodynamic performance data in terms of pressure, temperature, mass flow, as well as humidity under a wide-range of ECS healthy and faulty operational scenarios have been identified and elaborated. The selection of the required instrumentation set for experimental rig setup in terms of pressure, temperature, mass flow and humidity sensors have been described. The requirements for the sensor installation, calibration and test have also been discussed and illustrated. An initial ground test case was simulated for both healthy and PHX degraded cases are shown in this paper. It is identified that by simulating and experimentally verifying the simulation results can be used to develop a model-based diagnostic rule to detect and isolate faults in the ECS PACK. This combination of the GTF and a verified DT will open doors to numerous possibilities of formulating innovative IVHM technologies, enabling cost-effective maintainability of civil aircraft ECS systems.

\section{Acknowledgement}

This work has been funded by The Boeing Company as part of their industrial collaboration with the Cranfield University IVHM Centre. The authors would like to thank Boeing, Monarch Aircraft Engineering Ltd and the Cranfield Gas Turbine Engineering Laboratory for their support in this project.

\section{LIST OF ACRONYMS}

\begin{tabular}{|c|c|}
\hline$A P U$ & Auxiliary Power Unit \\
\hline$A D S$ & Air Distribution System \\
\hline$A C M$ & Air Cycle Machine \\
\hline$B A S$ & Bleed Air System \\
\hline$C H X$ & Condenser \\
\hline$D A Q$ & Data Acquisition Unit \\
\hline$D T$ & Digital Twin \\
\hline$E C S$ & Environmental Control System \\
\hline$F D I$ & Fault Detection and Isolation \\
\hline$G T F$ & Ground Test Facility \\
\hline$H P W S$ & High-Pressure Water Separator \\
\hline$P A C K$ & Passenger Air Conditioner \\
\hline$P H X$ & Primary Heat Exchanger \\
\hline$P V$ & PACK Valve \\
\hline$R H X$ & Reheater \\
\hline$R U L$ & Remaining Useful Life \\
\hline$S H X$ & Secondary Heat Exchanger \\
\hline$T C V$ & Temperature Control Valve \\
\hline$V \& V$ & Verification and Validation \\
\hline$W S$ & Water Separator \\
\hline
\end{tabular}

\section{REFERENCES}

Burroughs, J. D., \& Hammond, R. A. (1983). Control Analysis and Design Features of EASY5. In American Control Conference (pp. 58-63). San Francisco. doi:10.23919/ACC.1983.4788072

Butler, S. (2012). Prognostic Algorithms for Condition Monitoring and Remaining Useful Life Estimation. NATIONAL UNIVERSITY OF IRELAND, MAYNOOTH.Retrieved from http://core.kmi.open.ac.uk/download/pdf/11527019.pdf

C. Müller, D. Scholz, T. G. (2007). Dynamic Simulation of Innovative Aircraft Air Conditioning. In 1st CEAS European Air and Space Conference (pp. 869-878)

Cubillo, A., Perinpanayagam, S., \& Esperon-Miguez, M. (2016). A review of physics-based models in prognostics: Application to gears and bearings of rotating machinery. Advances in Mechanical Engineering, $\quad$ 8(8), 168781401666466. doi: $10.1177 / 1687814016664660$

Daigle, M. J., \& Goebel, K. (2011). A Model-Based 
Prognostics Approach Applied to Pneumatic Valves. International Journal of Prognostics and Health Management, 2, 1-16

Escobar, I. C. (2015). Condition Monitoring For Environmental Control Systems. Cranfield University.

Figuero, D. V. (2017). Diagnostic Capability for Environmental Control Systems. Universidad Politécnica de Madrid, Cranfield Univeristy

Jonsson, G. R., Lalot, S., Palsson, O. P., \& Desmet, B. (2007). Use of extended Kalman filtering in detecting fouling in heat exchangers. International Journal of Heat and Mass Transfer, 50, 2643-2655. doi:10.1016/j.ijheatmasstransfer.2006.11.025

Jung, D., Ng, K. Y., Frisk, E., \& Krysander, M. (2018). Combining model-based diagnosis and data-driven anomaly classifiers for fault isolation. Control Engineering Practice, 80(September), 146-156. doi:10.1016/j.conengprac.2018.08.013

Lightfoot, H., \& Greenough, R. M. (2016). State-of-the-art in integrated vehicle health management State-of-theart in integrated vehicle health, (March), 1-14. doi:10.1243/09544100JAERO446

Pang, L., Qu, H., \& Dong, S. (2008). Fault Diagnosis Algorithm for Heat Exchanger of Aircraft Environment Control System Based on Double Model Filter. ACTA AERONAUTICA ET ASTRONAUTICA SINICA, 29, 548-553

Saxena, A., \& Saad, A. (2007). Evolving an artificial neural network classifier for condition monitoring of rotating mechanical systems. Applied Soft Computing Journal, 7(1), 441-454. doi:10.1016/j.asoc.2005.10.001

Scholz, D., Giese, T., \& Erdmann, C. (2007). Flecs : Functional Library of the Environmental Control System - a Simulation Tool for the Support of Industrial Processes. In AST 2007, March 29-30, Hamburg, Germany

Steinkellner, S. (2011). Aircraft vehicle systems modeling and simulation under uncertainty. LINKÖPING University

Steinkellner, S., Andersson, H., \& Gavel, H. (2009). Modeling and simulation of Saab Gripen' $\mathrm{s}$ vehicle systems. AIAA, (August), 1-15

Tu, Y., \& Lin, G. (2010). Dynamic Simulation of Humid Air Environmental Control System. In 40th International Conference on Environmental Systems (pp. 1-10). doi:10.2514/6.2010-6305

Tu, Y., \& Lin, G. P. (2011). Dynamic Simulation of Aircraft Environmental Control System Based on Flowmaster. Journal of Aircraft, 48(6), 2031-2041.

\section{doi:10.2514/1.C031433}

Yang, X. Bin, Jin, X. Q., Du, Z. M., \& Zhu, Y. H. (2011). A novel model-based fault detection method for temperature sensor using fractal correlation dimension. Building and Environment, 46(4), 970979. doi:10.1016/j.buildenv.2010.10.030

\section{BIOGRAPHIES}

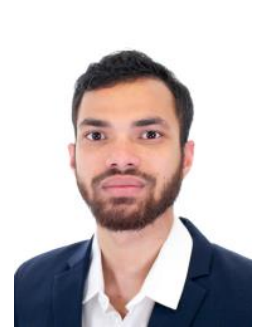

Shafayat Hasan Chowdhury is currently researching on IVHM technologies and tools at Cranfield University since 2017. Shafayat has previously worked at GE Aviation Wales as Operations Intern, taking responsibility of GE90 Gate 1. During his time at General Electric, he has designed the Visual Management System to enable Lean Manufacturing. He holds a Bachelor of Engineering in Aerospace Systems Engineering from Coventry University, UK. He is currently pursuing a $\mathrm{PhD}$ in IVHM at Cranfield University and is the student member of RAeS Cranfield Branch.

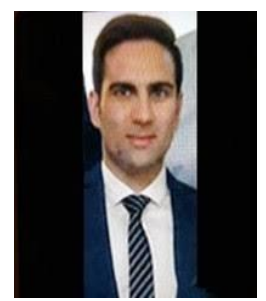

Fakhre Ali is a research fellow in simulation \& test at the Cranfield University, IVHM Centre. He holds a Mechanical engineering degree and an engineering doctorate in Aerospace Propulsion both from Cranfield University, UK. In his current role he is responsible for the successful planning, implementation and delivery of TRL $4-5$ level projects, dedicated towards identifying new IVHM solutions for various major civil aircraft sub-systems i.e. APU, ECS. He is a chartered Mechanical Engineer and a member of IMechE and RAeS.

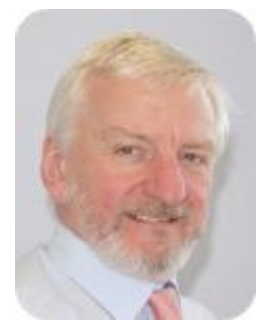

Ian K. Jennions. Ian's career spans over 40 years, working mostly for a variety of gas turbine companies. He has a Mechanical Engineering degree and a $\mathrm{PhD}$ in CFD both from Imperial College, London. He has worked for Rolls-Royce (twice), General Electric and Alstom in a number of technical roles, gaining experience in aerodynamics, heat transfer, fluid systems, mechanical design, combustion, services and IVHM. Ian moved to Cranfield in July 2008 as Professor and Director of the newly formed IVHM Centre. $\mathrm{He}$ is on the editorial Board for the International Journal of Condition Monitoring, a Director of the PHM Society, Chairman of SAE's IVHM Steering Group, contributing member of the SAE HM-1 IVHM committee, a Chartered Engineer and a Fellow of IMechE, RAeS and ASME. He is the editor of five SAE books and co-author of another one. 